\title{
Quantitative analysis of vitamin D and its main metabolites in human milk by supercritical fluid chromatography coupled to tandem mass spectrometry
}

\author{
J. M. Oberson ${ }^{1} \cdot$ S. Bénet ${ }^{1} \cdot$ K. Redeuil $^{1} \cdot$ E. Campos-Giménez ${ }^{1}$
}

Received: 29 May 2019 /Revised: 18 October 2019 / Accepted: 29 October 2019 /Published online: 12 December 2019

(C) The Author(s) 2019

\begin{abstract}
A novel method to quantitate vitamin D and its main metabolites (vitamin D3, vitamin D2, and their 25-hydroxy metabolites) in breast milk by supercritical fluid chromatography has been developed and fully validated. A small volume of sample $(1 \mathrm{~mL})$ is subjected to ethanolic protein precipitation and liquid-liquid extraction. Final extracts are derivatized with 4-phenyl-1,2,4triazoline-3,5-dione and vitamin D derivatives analyzed by supercritical fluid chromatography hyphenated to tandem mass spectrometry with atmospheric pressure chemical ionization. Multiple reaction monitoring is used for quantitation. Separation conditions were optimized using a gradient of methanol-water-ammonium formate into carbon dioxide. Make-up solvent was methanol containing ammonium formate. The quantitation limit reached levels as low as $50 \mathrm{pmol} / \mathrm{L}$, with intra- and inter-day relative standard deviations lower than $15 \%$ and $20 \%$ for all analytes. Accuracy was evaluated by spiking experiments and was well within acceptability ratios $( \pm 15 \%)$. The method was then applied to a subset of commercially available human milk samples. The newly developed method provides opportunities to determine the nutritional status of mother-infant dyads from a noninvasive measure, or for interventional or observational studies building knowledge on the composition of human milk.
\end{abstract}

Keywords Vitamin D · Human milk · Supercritical fluid chromatography $\cdot$ Tandem mass spectrometry

\section{Introduction}

Vitamin D is produced in humans from its precursor 7dehydrocholesterol by the action of sunlight [1]. The photoconversion of the precursor yields previtamin $\mathrm{D}$, which is converted to vitamin $\mathrm{D}$ by a temperature-dependent process. Vitamin D is transported to the liver and hydroxylated to 25hydroxyvitamin D (25OHD), the main circulating form. In the kidney, 25OHD is metabolized into the active form 1,25dihydroxyvitamin $\mathrm{D}$. Two forms of vitamin $\mathrm{D}$ are present in nature: cholecalciferol (vitamin D3), produced in mammals, and ergocalciferol (vitamin D2), produced in plants, fungi, and yeast. Both forms differ structurally by only a double

Electronic supplementary material The online version of this article (https://doi.org/10.1007/s00216-019-02248-5) contains supplementary material, which is available to authorized users.

E. Campos-Giménez

esther.campos-gimenez@rdls.nestle.com

1 Nestlé Research, Route du Jorat 57, Vers-chez-les-Blanc, 1000 Lausanne, Switzerland bond and a methyl group in the side chain (Fig. 1). The biological activity of both forms is considered equivalent in humans, although there is controversy around this statement [2-4]. International recommendations on food fortification (Codex Alimentarius CAC/GL 10/1979) do not distinguish between the two forms and thus, both need to be considered.

The first attempts to quantify vitamin D in human milk using chemical methods took place in the 1980's. Hollis et al. [5] used HPLC coupled to competitive protein binding detection and were first to quantitate vitamin $\mathrm{D}$ and its major metabolites. Several authors continued their work supporting the original idea that vitamin $\mathrm{D}$ and its 25 hydroxy derivatives constitute the main contributors to the vitamin D activity of human milk [6-9]. Nowadays, the most popular technique to analyze vitamin D in biological samples, besides immunoassays, is liquid chromatography coupled with tandem mass spectrometry [10-15]. Numerous methods have been published for human plasma or serum using liquid chromatography, but only a few for the analysis of milk [16-18], some of them $[16,17]$ using sample volumes larger than what is usually available from clinical studies (up to $10 \mathrm{~mL}$ ). 


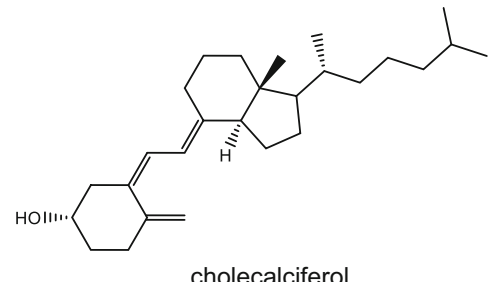

cholecalciferol

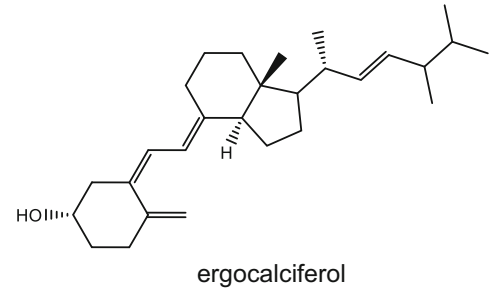

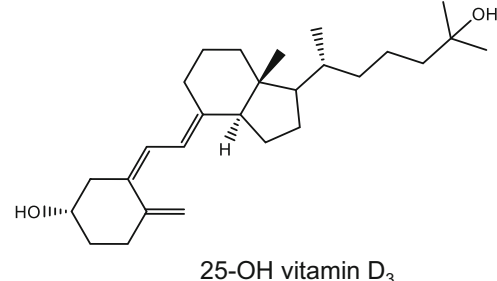

25-OH vitamin $\mathrm{D}_{3}$

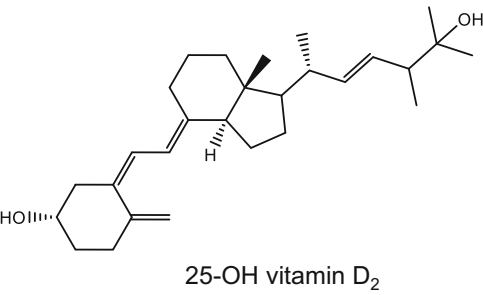

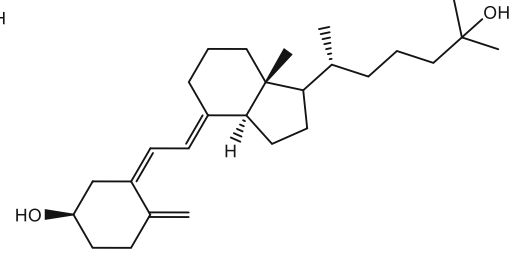

25-OH vitamin $\mathrm{D}_{3} \mathrm{C} 3$-epimer

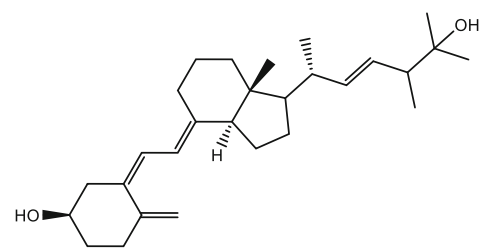

25-OH vitamin $D_{2}$ C3-epimer

Fig. 1 Chemical structure of vitamin D parent forms and main circulating metabolite 25-hydroxy vitamin D, together with C3 inactive epimer

Supercritical fluid chromatography (SFC), although originally reported more than 50 years ago [19], has only been used sporadically until the 1980 's. With new developments on safer and more robust instrumentation in the later decade, it has become a more popular technique in the field of bioanalysis and it is slowly replacing liquid chromatography (LC). Modern SFC uses subcritical carbon dioxide as the main mobile phase, which is modified by a gradient of polar organic solvents. Carbon dioxide shows clear advantages over the previously used fluids, it is safe and cheap, and its supercritical state is easily reached $\left(31.1^{\circ} \mathrm{C}, 73.9 \mathrm{bar}\right)$. When compared to LC, SFC separations are, in general, faster, provide sharper peaks, and improved resolution [20], meaning higher throughput and better efficiency [21, 22]. SFC hyphenated to tandem mass spectrometry (SFC-MS/MS) methods for the analysis of vitamin $\mathrm{D}$ and its metabolites in serum or plasma [23,24] or vitamin $\mathrm{D}$ in fortified food products [25] have been published but, to the best of our knowledge, no methods applied to the analysis of human milk are available.

In the present work, we aimed at developing a novel and fully validated method to quantify vitamin D and its main metabolites by supercritical fluid chromatography using less than $1 \mathrm{~mL}$ of human milk.

\section{Experimental}

\section{Chemicals}

Solvents used in sample preparation (acetone for HPLC, ethanol for chromatography, ethyl acetate reagent grade, nhexane for chromatography, isooctane for analysis) or for chromatographic analysis (acetonitrile and methanol for LCMS), as well as reagents (formic acid puriss., 4-phenyl-1,2,3triazoline-3,5-dione (PTAD), ammonium formate for spectroscopy) were sourced from Sigma-Aldrich (Buchs, Switzerland). Pressurized $\mathrm{CO}_{2}$ (99.9\%) was purchased from Carbagas (Gümligen, Switzerland).

\section{Human milk samples}

Commercial milk samples from human donors were obtained from Lee Biosolutions (Maryland Heights, USA). Samples were received frozen $\left(-20^{\circ} \mathrm{C}\right)$, thawn by placing them on a water bath at $40{ }^{\circ} \mathrm{C}$ for $1 \mathrm{~h}$, mixed by stirring, aliquoted into 2-mL aliquots, and stored at $-80^{\circ} \mathrm{C}$ prior to being used for development purposes. Maximum storage time was 3 months.

\section{Standards and calibration solutions}

25-Hydroxy cholecalciferol (25OHD3) $(50 \mu \mathrm{g} / \mathrm{mL}), 25$ hydroxy ergocalciferol (25OHD2) $(50 \mu \mathrm{g} / \mathrm{mL})$, cholecalciferol (D3) $(100 \mu \mathrm{g} / \mathrm{mL})$, and ergocalciferol (D2) $(1 \mathrm{mg} / \mathrm{mL})$ were purchased as ready-to-use solutions from Sigma-Aldrich (Buchs, Switzerland). Commercial solutions were combined into a standard solution containing $1 \mathrm{ng} / \mathrm{mL}$ of each of the four derivatives in ethanol.

Isotope labelled internal standards $\left({ }^{2} \mathrm{H}_{6}-\mathrm{D} 3,{ }^{2} \mathrm{H}_{6}\right.$-D2, $25 \mathrm{OH}^{2} \mathrm{H}_{6}-\mathrm{D} 3,25 \mathrm{OH}^{2} \mathrm{H}_{6}$-D2) were obtained from Chemaphor (Ottawa, Canada). Separate stock internal standard solutions $(100 \mu \mathrm{g} / \mathrm{mL}$ in ethanol) were prepared and combined into an internal standard (IS) solution containing $20 \mathrm{ng} / \mathrm{mL}$ of ${ }^{2} \mathrm{H}_{6}-\mathrm{D} 3,{ }^{2} \mathrm{H}_{6}-\mathrm{D} 2,25 \mathrm{OH}^{2} \mathrm{H}_{6}-\mathrm{D} 3$, and $25 \mathrm{OH}^{2} \mathrm{H}_{6}$ D2. All solutions were kept at $-18^{\circ} \mathrm{C}$ before use, for a maximum of 1 year.

Calibration standards were constructed by combining 25 $\mu \mathrm{L}$ of the IS solution and incremental volumes of the standard solution into 1.5-mL Eppendorf® tubes, drying over a stream of nitrogen and redissolving into $1 \mathrm{~mL}$ of isooctane for PTAD derivatization. Twenty-five microliters of PTAD solution (10 
$\mathrm{mg} / \mathrm{mL}$ in acetone) was added; the tubes were shaken and placed in the darkness for $1 \mathrm{~h}$. After the addition of $100 \mu \mathrm{L}$ of acetonitrile-water $(80: 20, \mathrm{v} / \mathrm{v})$, the tubes were vortexed and centrifuged at $10,000 \times g$ for $5 \mathrm{~min}$ for phase separation. Final concentrations after derivatization (final volume $100 \mu \mathrm{L}$ ) were $0,0.2,0.5,1,2,5$, and $10 \mathrm{ng} / \mathrm{mL}$.

Additional metabolites used for method development (1,25-dihydroxy-D2, 1,25-dihydroxy-D3, 24,25-dihydroxyD2, and 24,25-dihydroxy-D3) were purchased from SigmaAldrich (Buchs, Switzerland). Individual solutions were prepared in ethanol, and PTAD derivatized following the same protocol as for the rest of standards. Final concentration after derivatization was $100 \mathrm{ng} / \mathrm{mL}$.

\section{Choice of the chromatographic column}

Nine chromatographic columns were chosen for screening. Individual derivatized solutions $(100 \mathrm{ng} / \mathrm{mL})$ were injected $(3 \mu \mathrm{L})$ on all the columns. Methanol-water $(98: 2, \mathrm{v} / \mathrm{v})$ containing $10 \mathrm{mM}$ ammonium formate was used as organic modifier. Flow rate was adapted to each column tested according to the backpressure developed during the eluting gradient. The percentage of organic modifier was held at $0.5 \%$ from time 0 to $0.2 \mathrm{~min}$ and then slowly increased from $0.5 \%$ at $0.2 \mathrm{~min}$ to $50 \%$ in $8 \mathrm{~min}$, maintained for $10 \mathrm{~min}$ at $50 \%$ and decreased to initial conditions for the next injection. Column temperature was maintained constant at $45^{\circ} \mathrm{C}$ and atmospheric back pressure regulator (ABPR) at 128 bar. Make-up solvent was $10 \mathrm{mM}$ ammonium formate in methanol at a flow rate of 0.4 $\mathrm{mL} / \mathrm{min}$. Once the chromatographic column was chosen, elution gradient was optimized to achieve best separation.

\section{Optimization of sample preparation}

The effect of saponification ( $\mathrm{SN}$ ) as well as protein precipitation (PP) on the extraction efficiency was studied using the post-extraction addition method. IS solution $(25 \mu \mathrm{L})$ was added to $1 \mathrm{~mL}$ of breast milk and subjected to either $\mathrm{SN}$ or PP followed by liquid-liquid extraction (LLE). In parallel, 1 $\mathrm{mL}$ of the same non-spiked milk was extracted and the IS solution $(25 \mu \mathrm{L})$ added just before PTAD derivatization. LLE and SN conditions were based on previously published methodologies $[26,27]$ and adapted to the low volumes of sample available. Extraction solvent mixtures of slightly different polarities were also tested. Extraction efficiency was calculated from the relative difference between peak response in the extracts spiked before and after extraction.

\section{Sample preparation}

Human milk samples were placed in a water bath at $40{ }^{\circ} \mathrm{C}$ for $1 \mathrm{~h}$ and thoroughly mixed prior to extraction.
Working into a Biosafety cabinet Class II, $1 \mathrm{~mL}$ of milk, 1 $\mathrm{mL}$ of ethanol, and $25 \mu \mathrm{L}$ of IS solution were mixed in a $15-\mathrm{mL}$ Falcon ${ }^{\circledR}$ polypropylene centrifuge tube. From this point, work was performed following common chemical safety regulations. A total of $2.5 \mathrm{~mL}$ of a mixture of n-hexane and ethyl acetate $(90: 10, \mathrm{v} / \mathrm{v})$ was added; the tube was tightly closed and shaken in a Geno Grinder® for $3 \mathrm{~min}$. Centrifugation at $2500 \times \mathrm{g}$ for 5 min was applied for phase separation. The upper organic phase was then transferred into an 8 -mL glass tube and dried down to almost dryness under a stream of nitrogen. The liquid/ liquid extraction process was repeated, and the upper organic phases combined into the same glass tube. The combined organic phases were dried down to almost dryness under a stream of nitrogen, redissolved into $400 \mu \mathrm{L}$ of the hexane-ethyl acetate mixture. The organic phase was transferred quantitatively into a 1.5-mL Eppendorf tube ${ }^{\circledR}$. Two additional $400 \mu \mathrm{L}$ portions of hexane-ethyl acetate mixture were added to rinse the glass tube and transferred into the same Eppendorf tube ${ }^{\circledR}$. The combined portions were then dried under a stream of nitrogen. Hundred $(100 \pm 10)$ milligrams of sodium sulfate and $1 \mathrm{~mL}$ of isooctane were added. The tubes were vortexed and centrifuged at $10,000 \times g$ for $5 \mathrm{~min}$. The dried liquid phase was transferred into another Eppendorf tube ${ }^{\circledR}$ for PTAD derivatization.

PTAD derivatization was adapted from a previously published protocol [25], and $25 \mu \mathrm{L}$ of a PTAD solution $(10 \mathrm{mg} / \mathrm{mL}$ in acetone) was added. The tubes were shaken and placed in the darkness for $1 \mathrm{~h}$. One hundred microliters of acetonitrile:water $(80: 20, \mathrm{v} / \mathrm{v})$ were added, and the tubes were vortexed for a few seconds and centrifuged at $10,000 \times g$ for $5 \mathrm{~min}$. About $50 \mu \mathrm{L}$ of the lower phase was transferred to a low-volume LC vial and $3 \mu \mathrm{L}$ injected into the chromatographic system.

\section{Analytical instrumentation}

Analysis was performed on an Acquity ${ }^{\circledR} \mathrm{UPC}^{2 \mathrm{TM}}$ system (Waters, Milford, MA, USA) equipped with a binary pump, an autosampler, a column manager oven, an atmospheric back pressure regulator (ABPR), and a make-up pump coupled to a Waters Xevo ${ }^{\mathrm{TM}}$ TQ-S mass spectrometer. The whole system was controlled by MassLynx ${ }^{\mathrm{TM}} 4.1$ software (Waters, Milford, MA, USA).

\section{Mass spectrometry instrumental conditions}

Mass spectrometric detection was carried out on Atmospheric Pressure Chemical Ionization operating in positive mode at unit resolution $\left(\mathrm{APCI}^{+}\right)$. Optimal parameters were needle corona at $4 \mathrm{kV}$, ion source temperature $150^{\circ} \mathrm{C}$, probe temperature $450{ }^{\circ} \mathrm{C}$, cone gas flow $150 \mathrm{~L} / \mathrm{h}$, collision gas flow 0.15 $\mathrm{mL} / \mathrm{min}$. Argon was used as collision gas, while nitrogen was set as desolvation gas $(650 \mathrm{~L} / \mathrm{h})$. Multiple reaction monitoring (MRM) was used and defined selected ions for detection and quantitation of each analyte are shown in Table 1. 
Table 1 APCI+ parameters for each vitamin D-related compound. Precursor ion was the predominant molecular ion. The pair precursor ion/product ion was used for quantitation

\begin{tabular}{llccc}
\hline & Cone voltage $(\mathrm{V})$ & Collision energy $(\mathrm{eV})$ & Precursor ion $(\mathrm{m} / \mathrm{z})$ & Product ion $(\mathrm{m} / \mathrm{z})$ \\
\hline D2-PTAD & 30 & 15 & 572.4 & 298.1 \\
D3-PTAD & 30 & 15 & 560.4 & 298.1 \\
25OHD2-PTAD & 30 & 17 & 570.4 & 298.1 \\
25OHD3-PTAD & 30 & 15 & 558.4 & 298.1 \\
3epi-25OHD2-PTAD & 30 & 20 & 570.4 & 298.1 \\
3epi-25OHD3-PTAD & 30 & 15 & 558.4 & 298.1 \\
1,25diOHD2-PTAD & 30 & 15 & 586.4 & 298.1 \\
1,25diOHD3-PTAD & 30 & 15 & 574.4 & 298.1 \\
24,25diOHD2-PTAD & 30 & 30 & 586.4 & 298.1 \\
24,25diOHD3-PTAD & 30 & 30 & 574.4 & 298.1 \\
\hline
\end{tabular}

\section{Calculations}

TargetLynx ${ }^{\mathrm{TM}}$ software package (Waters, Milford, MA, USA) was used for automated peak integration and data processing. Isotope labelled internal standards were used for calibration on a solvent-based matrix. A weighed $(1 / \mathrm{x})$ linear regression model from peak area ratios (peak area of analyte/peak area of labelled internal standard) versus concentration was automatically constructed and used for calculations. Results were expressed as $\mathrm{ng} / 100 \mathrm{~mL}$ according to final dilution factor (1 $\mathrm{mL}$ milk/100 $\mu \mathrm{L}$ ).

\section{Method validation}

The optimized method was submitted to validation following Guidance for Industry on Bioanalytical Method Validation (US Dpt. of Health and Human Services, FDA, May 2001). Selectivity, sensitivity, and calibration linearity were evaluated. Matrix effect was studied using the post-extraction addition method. A standard reference material (SRM 1849a Infant/Adult Formula) from the National Institute of Standards and Technology with certified vitamin D3 value $(111 \mu \mathrm{g} / \mathrm{kg} \pm 17 \mu \mathrm{g} / \mathrm{kg})$ [28] was used as reference due to the absence of a human milk reference material. One gram of powder was diluted into a final volume of $1000 \mathrm{~mL}$ to provide a liquid sample containing a concentration of vitamin D3 close to the expected values in human milk (11.1 ng/100 $\mathrm{mL}$ ). One milliliter of the diluted powder was analyzed on duplicate on ten different days. The accuracy and precision of the method were further evaluated by spiking a human milk sample at different concentration levels and carrying out the full sample treatment. Accuracy was evaluated as the difference between the amount in the spiked sample and the amount in the non-spiked sample $v s$ the spiked concentration (recovery). Standard deviation of repeatability ( $\mathrm{Sr}$ ) and intermediate reproducibility ( $\mathrm{SiR}$ ) calculated according to ISO-5725 from the duplicate analysis were used as estimates of within- and between-day method variability (precision).

\section{Results and discussion}

\section{Method optimization}

\section{Choice of metabolites and chromatographic conditions}

Table 2 shows retention time of the PTAD derivatives on each of the columns screened (see Electronic Supplementary Material (ESM) Figs. S1 to S9 for example chromatograms). The choice of the metabolites to be included in the separation was based on previous reports. The main components of the vitamin D activity in human milk are the parent compounds (D2 and D3) and their 25OH metabolites [5-9], while the contribution of other metabolites (i.e., 1,25-dihydroxy-D2, 1,25-dihydroxy-D3, 24,25-dihydroxy-D2, and 24,25-dihydroxy-D3) is considered negligible $[6,7]$. The reason to include them in the method development was to ensure that, even if they were present in very small quantities, they would not interfere with the main forms compromising method specificity. Methanol was the only organic modifier tested, since better separations and higher sensitivities have been reported using methanol as compared to acetonitrile in SFC $[15,17]$. The introduction of methanol as organic modifier produced increased backpressure, but this effect was controlled by reducing total flow rate on the second part of the elution gradient. Based on previous experiences [25], ammonium formate and a small percentage of water were included in the mobile phase. Requirements for the choice of the column were mass and/or chromatographic separation. Special interest was given to metabolites that could potentially interfere with the most relevant compounds (D2, D3, 25OHD2, 25OHD3). This was the case of the separation between the inactive 3-epi-25OH-D (Fig. 1) and its biologically active isomer 25OH-D [29]. Some of the individual compounds were detected as double peaks (compounds with two retention times reported in Table 2), i.e., D2-PTAD on a Waters Torus ${ }^{\mathrm{TM}}$ 1-AA column (ESM Fig. S1). PTAD derivatization produces two epimers, $6 \mathrm{~S}$ and $6 \mathrm{R}$, which are chromatographically separated depending on the stationary and mobile phases, as observed in Table 2 . Although both 


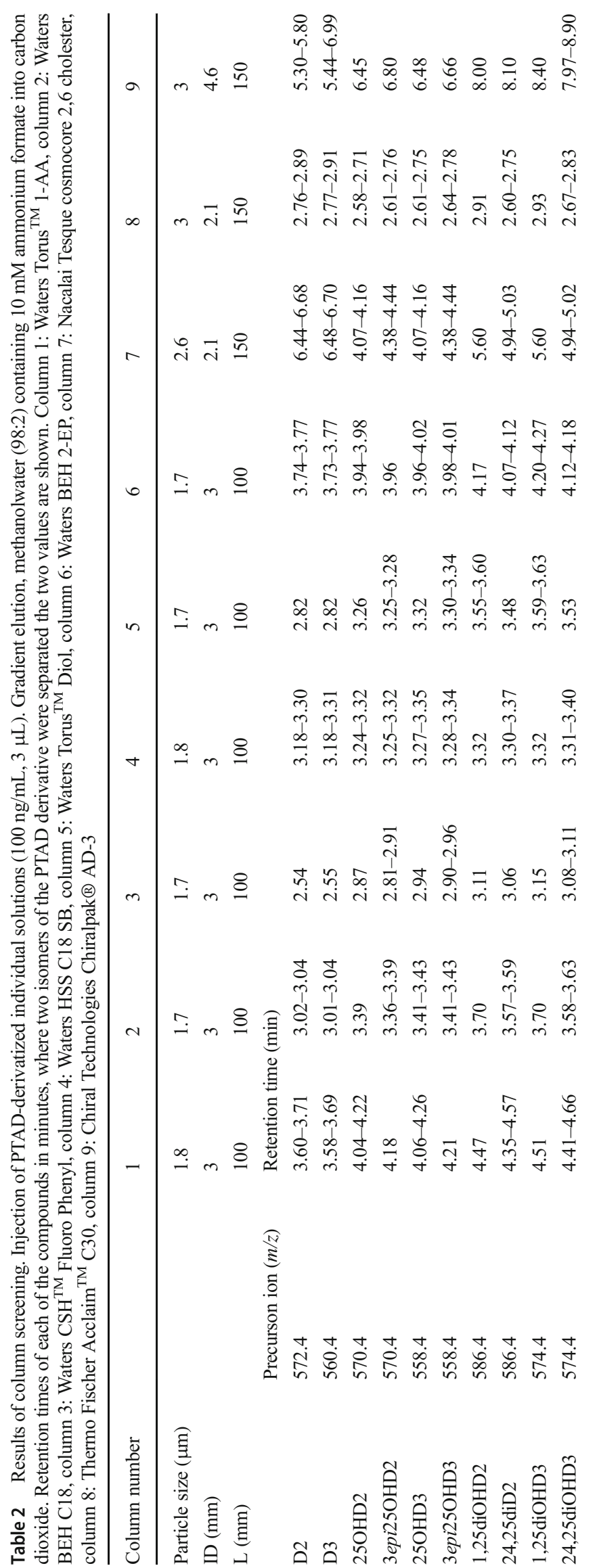


peaks can be used for quantitation, their chromatographic separation might not be advantageous for quantitative purposes, as previously reported by other authors [15]. In order to maximize sensitivity, the columns providing single peaks for the main PTAD derivatives were preferred.

Two columns (Chiralpak® AD-3 and $\mathrm{CSH}^{\mathrm{TM}}$ FluoroPhenyl) met the initial requirements (mass and/or chromatographic separation of all compounds). The $\mathrm{CSH}^{\mathrm{TM}}$ FluoroPhenyl column was retained for validation since it provided baseline resolution for all compounds not resolved by their mass fragmentation, with initially shorter elution times and better peak shapes than the Chiralpak ${ }^{\circledR}$ AD-3. Main metabolites (25OHD2 and 25OHD3) appeared as a single peak, facilitating integration and quantitation. After further optimization of the gradient, the 3-epi isomers of 25OHD were well separated, appearing as double peaks as seen in Fig. 2.

Validation was then carried out on a Waters Acquity ${ }^{\circledR}$ $\mathrm{UPC}^{2 \mathrm{TM}} \mathrm{CSH}^{\mathrm{TM}}$ Fluoro-Phenyl, $3.0 \times 100 \mathrm{~mm}, 1.7 \mu \mathrm{m}$ column. Compounds were eluted using an optimized gradient of methanol-water (98:2) containing $10 \mathrm{mM}$ ammonium formate in $\mathrm{CO}_{2}$ (Table 3). Column temperature was set at $45^{\circ} \mathrm{C}$ and ABPR at 128 bar. Total run time was 9 min. Make-up solvent was $10 \mathrm{mM}$ ammonium formate in methanol at a flow rate of $0.4 \mathrm{~mL} / \mathrm{min}$.

\section{Injection volume}

One of the drawbacks of SFC as compared to LC is the low volume of sample that can be injected without observing peak distortion [23]. This becomes critical when analyzing molecules present at low levels, in which increasing injection volume might be a valid option to maximize response. It has been shown that the volume that can be injected depends on the analyte, the organic modifier, and the chromatographic conditions and should be investigated on each method development $[23,30]$. In our previous work [25], we demonstrated that PTAD derivatives of vitamin $\mathrm{D}$ did not show peak distortion at volumes as high as $10 \mu \mathrm{L}$ on a Waters Acquity ${ }^{\circledR} \mathrm{UPC}^{2 \mathrm{TM}}$ Torus $^{\mathrm{TM}}$ 1-Aminoanthracene, $3.0 \times 100 \mathrm{~mm}, 1.8 \mu \mathrm{m}$ column using same mobile phase as in the method here described. In an effort to explore all possibilities to increase sensitivity without compromising method performance, 3 and $10 \mu \mathrm{L}$ of calibration standards were injected on the $\mathrm{CSH}^{\mathrm{TM}}$ Fluoro Phenyl column. On the contrary to our previous observations on a Torus $^{\mathrm{TM}}$ 1-Aminoanthracene column with the same organic modifier and similar gradient, the injection volume could not be increased without peak distortion (Fig. 3), confirming the method dependency and the need for optimization on each individual development.
Fig. 2 Chromatographic separation of 25-hydroxy vitamin D-PTAD derivatives and their C3 inactive epimer on a Waters $\mathrm{CSH}^{\mathrm{TM}}$ Fluoro Phenyl column $(1.7 \mu \mathrm{m}, 3 \times 100 \mathrm{~mm})$. Gradient of methanol/water $(98: 2, \mathrm{v} / \mathrm{v})$ containing $10 \mathrm{mM}$ ammonium formate as organic modifier on carbon dioxyde. Column temperature $45^{\circ} \mathrm{C}$, Atmospheric Back Pressure Regulator 128 bar. Make-up solvent was $10 \mathrm{mM}$ ammonium formate in methanol, flow rate $0.4 \mathrm{~mL} / \mathrm{min}$
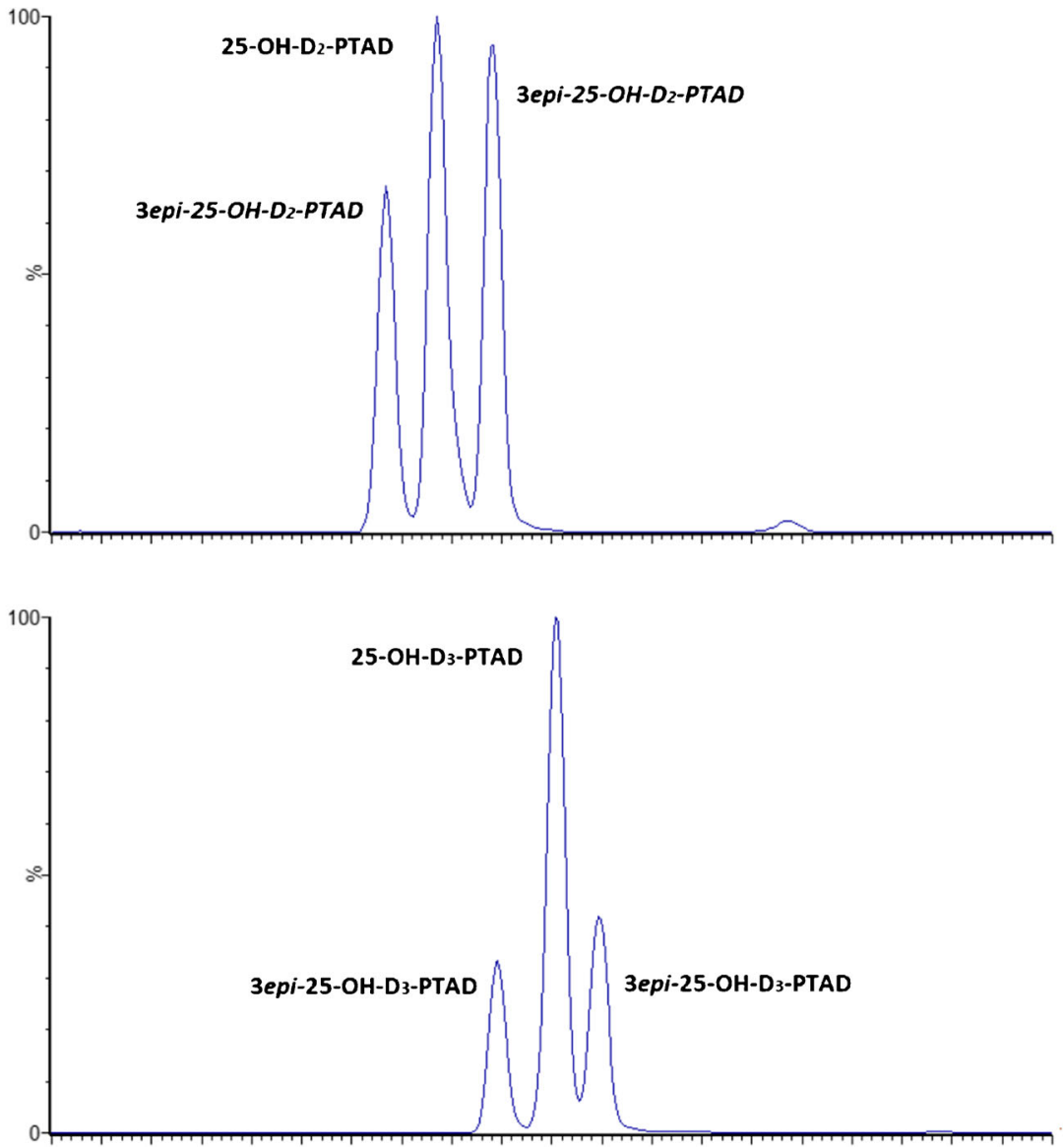
Table 3 SFC optimized elution gradient. Mobile phase A: carbon dioxide. Mobile phase B: $10 \mathrm{mM}$ ammonium formate in methanol:water (98:2)

\begin{tabular}{llll}
\hline Time (min) & $\begin{array}{l}\text { Flow rate } \\
(\mathrm{mL} / \mathrm{min})\end{array}$ & $\begin{array}{l}\text { Mobile } \\
\text { phase A (\%) }\end{array}$ & $\begin{array}{l}\text { Mobile } \\
\text { phase B (\%) }\end{array}$ \\
\hline 0.0 & 3.00 & 99.5 & 0.5 \\
0.5 & 3.00 & 99.5 & 0.5 \\
5.0 & 2.75 & 92.0 & 8.0 \\
6.0 & 1.75 & 70.0 & 30.0 \\
7.0 & 1.75 & 70.0 & 30.0 \\
7.8 & 1.75 & 99.5 & 0.5 \\
8.5 & 3.00 & 99.5 & 0.5 \\
9.0 & 3.00 & 99.5 & 0.5 \\
\hline
\end{tabular}

\section{Sample preparation}

Gomes et al. [17] reported the comparison between saponification (SN) and protein precipitation (PP) followed by liquidliquid extraction (LLE) and showed better efficiency of the extraction when saponification was avoided, most likely due to degradation in alkaline media. Due to the difficulties to find samples completely devoid of vitamin D metabolites suitable to be used on spiking experiments, we tested the effect of SN as well as PP both followed by LLE, on the recovery of internal standards (Table 4). SN is the recognized method of choice for the analysis of the parent compounds (vitamin D) in milk products [31]. However, the recovery of the $25 \mathrm{OH}$ metabolites was strongly affected by the $\mathrm{SN}$, as well as by the polarity of the extracting solvent. As expected, increasing the polarity of the extraction solvent increased the recovery, but the values did not exceed $70 \%$. When SN was omitted, the results of the PP followed by LLE showed recovery rates between 70 and $107 \%$ for all metabolites and conditions tested, with slightly higher percentages when ethanol was used as protein precipitant rather than methanol. Ethanol was then preferred over methanol due to lower toxicity. Furthermore, the use of methanol produced, in some cases, emulsions during LLE, making phase separation more difficult than with ethanol. Increasing the polarity of the extraction solvent did not increase recovery on any of the analytes. Experiments on the effect of repeated extraction showed that two LLE steps were sufficient and a third cycle did not improve results. PP followed by LLE was then preferred over SN.

\section{Method performance}

\section{Selectivity}

Selectivity was ensured by the use of derivatization combined with chromatographic separation and tandem mass spectrometry. Indeed, PTAD derivatization efficiently removes interferences by shifting $m / z$ to higher values and boosting sensitivity by increasing ionization efficiency [15, 25]. MRM chromatograms of each of the analytes showed absence of interfering peaks (Fig. 4). Due to the low concentrations, only one MRM
Fig. 3 Effect of injection volume on peak shape of vitamin D2 and vitamin D3 on a Waters Acquity® UPC2TM CSHTM FluoroPhenyl, $3.0 \times 100 \mathrm{~mm}, 1.7 \mu \mathrm{m}$ column. Gradient elution with methanol containing ammonium formate as organic modifier
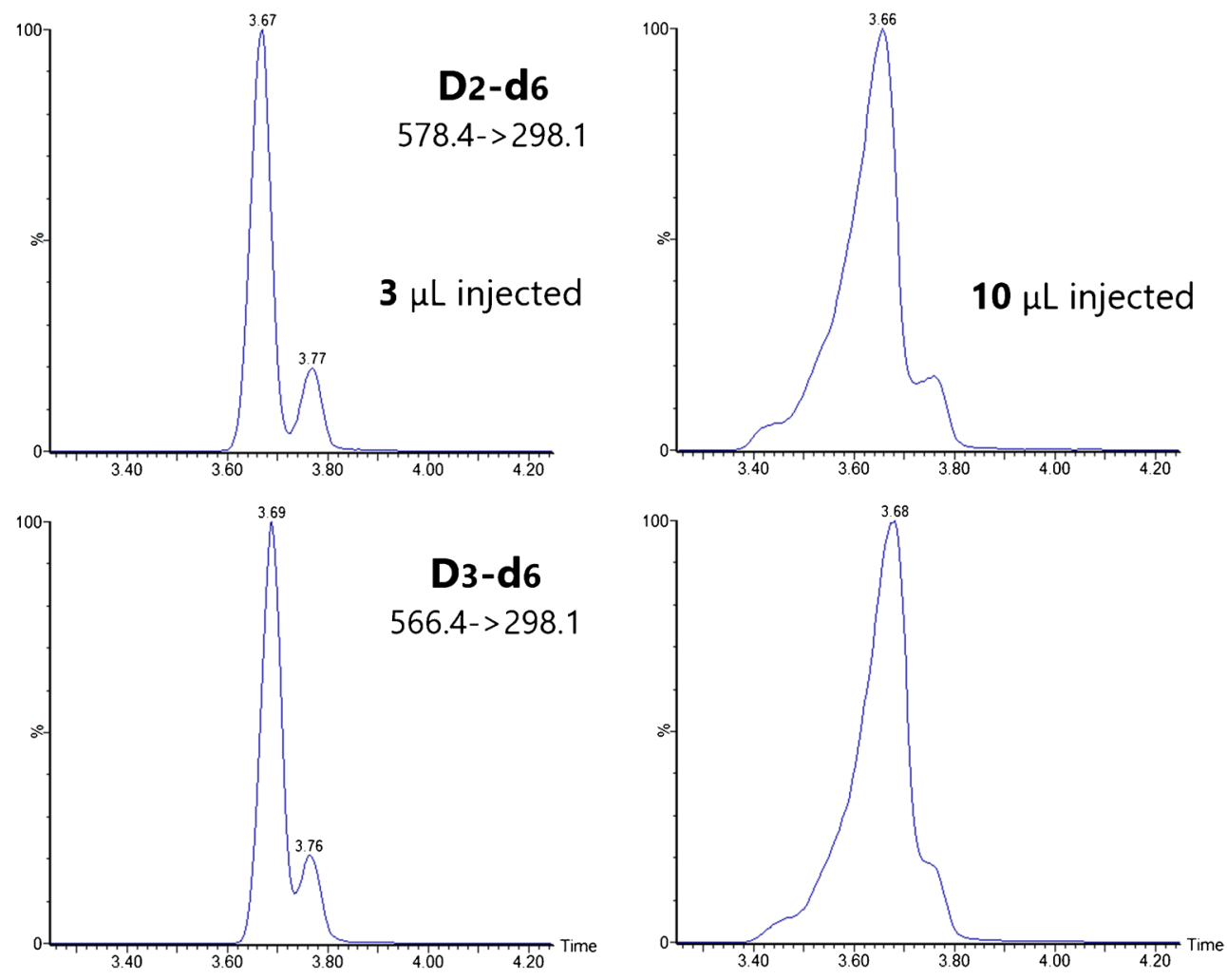
Table 4 Optimization of sample preparation using post-extraction addition method. Extraction efficiency calculated from the relative difference between peak response in a human milk sample spiked before and after extraction. Composition of extraction solvents and number of extraction cycles given in brackets. $P P$ protein precipitation, $L L E$ liquidliquid extraction, $S N$ saponification

\begin{tabular}{lllll}
\hline & \multicolumn{4}{l}{ Extraction efficiency (\%) } \\
\cline { 2 - 5 } & D3-d6 & D2-d6 & 25-OHD3-d6 & 25-OH D2-d6 \\
\hline SN (ethanol), LLE (hexane) & 67 & 73 & 10 & 5 \\
SN (ethanol), LLE (hexane-ethyl acetate 9:1) & 113 & 114 & 37 & 31 \\
SN (ethanol), LLE (hexane-ethyl acetate 7:3) & 144 & 136 & 65 & 68 \\
PP (ethanol), LLE (hexane-ethyl acetate 9:1, 9:1) & 107 & 112 & 106 & 101 \\
PP (ethanol), LLE (hexane-ethyl acetate 9:1, 9:1,9:1) & 103 & 105 & 106 & 101 \\
PP (ethanol), LLE (hexane-ethyl acetate 9:1, 4:1, 4:1) & 67 & 71 & 85 & 96 \\
PP (ethanol), LLE (hexane-ethyl acetate 9:1, 4:1, 3:1) & 77 & 71 & 85 & 102 \\
PP (methanol), LLE (hexane-ethyl acetate 9:1, 4:1, 3:1) & 70 & 68 & 95 & 93 \\
PP (methanol), LLE (hexane-ethyl acetate 9:1, 4:1, 3:1) & 67 & 68 & 90 & 89
\end{tabular}

transition, the predominant ion, could be monitored. The use of a second transition for confirmation could not be implemented, making separation from interferences critical for proper quantitation.

\section{Matrix effect and calibration}

Since human milk composition may vary greatly, it evolves within lactation and shows extreme compositional differences between individuals; matrix effect can drastically change from one sample to the next. In the sample studied, matrix effect (ion suppression), evaluated using the post-extraction addition method, was lower than $20 \%$ for the parent compounds (D2 and D3) and lower than 5\% for the metabolites (25OHD).
Strategies to account for matrix effects include the use of matrix-match calibration. In an ideal situation, the exact same sample is used to build the calibration model. In routine work, a "pooled" sample representing the whole population is used to build the calibration. A calibration curve specific to each sample would be necessary to ensure accuracy. Due to the difficulties to obtain high volumes of milk to prepare calibration curves in addition to the sample itself, together with the burden of such practice in routine laboratories, the use of isotope labelled internal standards provides an excellent solution [32]. The commercial availability of isotope labelled internal standards for each of the compounds considered allowed us to perform calibration "in-solvent" instead of matrix-matched without compromising method performance.
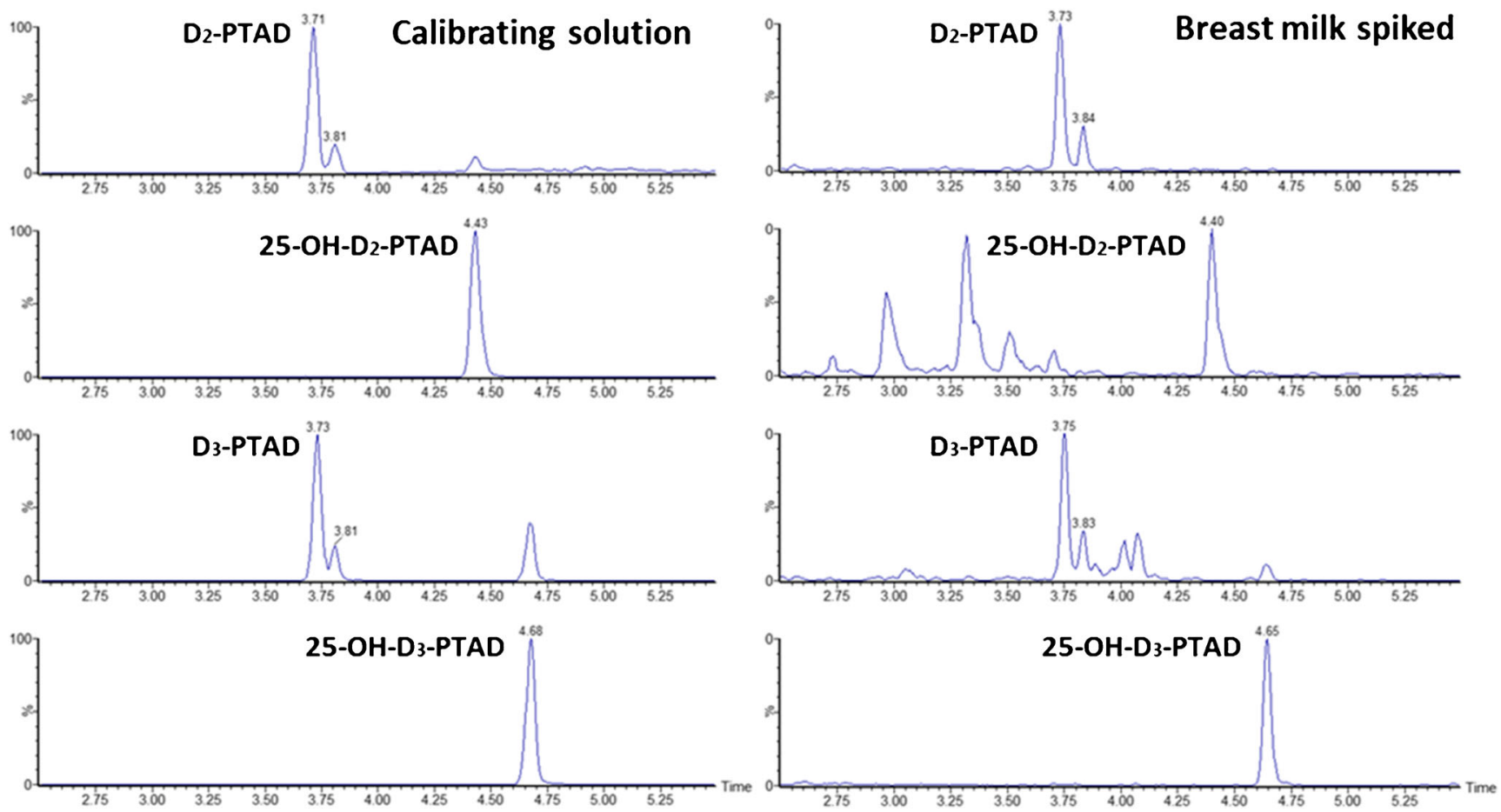

Fig. 4 MRM chromatograms of a calibrating solution $(2 \mathrm{ng} / \mathrm{mL})$ and a spiked human milk $(20 \mathrm{ng} / 100 \mathrm{~mL})$ 


\section{Linearity and limit of quantitation}

Linearity of calibration (peak area ratio $v s$ concentration) was demonstrated over the full analytical range ( 0.6 to $30 \mathrm{ng}$ injected). Coefficient of determination $\left(r^{2}\right)$ was higher than 0.990 for all the analytes. Lower limit of quantitation (LLOQ) was established as the lowest level in the calibration curve ( $0.6 \mathrm{ng}$ injected), which presented response 5 times higher than the instrumental noise together with accuracy (estimated $v$ sominal concentration) between 80 and $120 \%$. All other levels of the calibration curve presented maximum $10 \%$ deviation from nominal concentration. Method lower limits of quantitation were established taking into account sample dilution factors $(1 \mathrm{~mL} / 100 \mu \mathrm{L})$ applied to the instrumental LLOQ and were as low as $2 \mathrm{ng} / 100 \mathrm{~mL}$ (equivalent to $50 \mathrm{pmol} / \mathrm{L}$ ) for all analytes.

\section{Accuracy}

The absence of certified reference materials undermines the determination of accuracy on the analysis of human milk. Standard Reference Material 1849a (a milk-based, hybrid infant/adult nutritional formula) from the National Institute for Standards and Traceability (NIST) provided a partial solution for at least one of the analytes (D3). Analysis of SRM 1849a diluted to vitamin D3 levels close to expected levels in human milk provided an average result of $9.42 \pm 1.96 \mathrm{ng} / 100$ $\mathrm{mL}$ (average of $n=10$ duplicate determinations \pm standard deviation, expressed on the diluted sample). This result is well within the certified limits $11.1 \pm 1.7 \mathrm{ng} / 100 \mathrm{~mL}$ (calculated taking into account dilution). Despite the differences in matrix and the fact that vitamin D3 is fortified in the SRM, while it is naturally present in human milk, the results provided confidence on the approach. To our knowledge, no certified or reference human milk material containing 25OHD is commercially available.
Method accuracy was further evaluated from the analysis of QC samples at different levels on repeated non-consecutive days (Table 5). Method accuracy estimated from spiking at two different levels was within acceptability limits $( \pm 15 \%)$ and not statistically different from $100 \%$ for all compounds and levels. Within and between-day variability was calculated (Table 5). Relative standard deviation of repeatability (RSr) was below $10 \%$, except for the native $25 \mathrm{OH}$ derivatives concentration. In the case of 25OHD3 $(19.4 \mathrm{ng} / 100 \mathrm{~mL})$, it remained below 15\%. 25OHD2 was present at LLOQ levels $(2.7 \mathrm{ng} / 100 \mathrm{~mL})$, showing variability as high as $37 \%$.

\section{Application of the method to human milk samples}

The method was applied to commercial human milk samples from healthy single donors (Lee Biosolutions, Maryland Heights, USA). The results (Table 6) show the presence of metabolites of vitamin D3 as the main contributors to the total vitamin $\mathrm{D}$ activity, while the presence of low levels of vitamin D2 occurs most likely from dietary intake of foods such as mushroom or from supplementation. The concentrations of the individual metabolites in milk correspond to maternal circulating levels and are expected to be around a hundred times lower than those $[33,34]$. In the subset of samples here analyzed, all the results were consistent with previously reported data in Western populations [18]. It has been reported that minimal day-to-day variation is expected on the $25 \mathrm{OH}$ metabolites, while the amount of the parent compound may vary greatly with UV exposure or intake [34]. In this subset of samples, we confirmed this observation among different individuals, with a similar concentration of $25 \mathrm{OHD} 3$ in all the samples, consistent with expected levels, and very variable values on the parent forms.
Table 5 Intra- and inter-day variability on a human milk sample. Analysis performed on $n$ nonconsecutive days in duplicate. n.a. not applicable, $R S r$ relative standard deviation of repeatability (within-day variability), $R S i R$ relative standard deviation of intermediate reproducibility (betweenday variability)

\begin{tabular}{|c|c|c|c|c|c|}
\hline & & Vitamin D2 & Vitamin D3 & 25-OHD2 & 25-OHD3 \\
\hline \multirow{3}{*}{$\begin{array}{l}\text { Native amount } \\
n=6\end{array}$} & Average $(\mathrm{ng} / 100 \mathrm{~mL})$ & 2.8 & 22.3 & $<2$ & 19.4 \\
\hline & $\mathrm{RSr}$ & $37.3 \%$ & $10.8 \%$ & n.a. & $12.3 \%$ \\
\hline & $\mathrm{RSiR}$ & $32.7 \%$ & $16.7 \%$ & n.a. & $13.7 \%$ \\
\hline \multirow{4}{*}{$\begin{array}{l}\text { Spiked }(+20) \\
n=10\end{array}$} & Average (ng/100 mL) & 25.5 & 49.8 & 20.8 & 39.6 \\
\hline & Accuracy & $112.0 \%$ & $117.7 \%$ & $104.2 \%$ & $100.4 \%$ \\
\hline & $\mathrm{RSr}$ & $10.8 \%$ & $7.1 \%$ & $9.1 \%$ & $6.9 \%$ \\
\hline & RSiR & $26.9 \%$ & $11.3 \%$ & $14.7 \%$ & $10.7 \%$ \\
\hline \multirow{4}{*}{$\begin{array}{l}\text { Spiked }(+40) \\
n=10\end{array}$} & Average (ng/100 mL) & 44.7 & n.a. & 43.4 & n.a. \\
\hline & Accuracy & $104.3 \%$ & n.a. & $108.5 \%$ & n.a. \\
\hline & $\mathrm{RSr}$ & $9.6 \%$ & n.a. & $8.5 \%$ & n.a. \\
\hline & RSiR & $14.9 \%$ & n.a. & $14.4 \%$ & n.a. \\
\hline
\end{tabular}


Table 6 Vitamin D metabolites in a subset of commercial human milk samples. Antirachitic activity (ARA) calculated as $1 \mathrm{IU} /$ $\mathrm{L}=25 \mathrm{pg} / \mathrm{mL}$ vitamin $\mathrm{D}=5 \mathrm{pg} /$ $\mathrm{mL}$ vitamin 25OHD [18]. Average of triplicate analysis \pm standard deviation

\begin{tabular}{lllllll}
\hline & D2 & D3 & 25OHD2 & 25OHD3 & ARA & \% 25OH ARA \\
& ng/100 mL & & & & IU/L & \\
Sample 1 & $4.2 \pm 0.6$ & $25.8 \pm 0.8$ & $<2$ & $18.7 \pm 0.3$ & 47.7 & $78 \%$ \\
Sample 2 & $3.8 \pm 0.3$ & $6.5 \pm 0.8$ & $<2$ & $18.7 \pm 1.9$ & 40.0 & $93 \%$ \\
Sample 3 & $4.0 \pm 0.8$ & $19.5 \pm 0.9$ & $<2$ & $12.8 \pm 1.3$ & 33.4 & $77 \%$ \\
Sample 4 & $3.7 \pm 1.0$ & $15.2 \pm 1.7$ & $<2$ & $25.7 \pm 1.1$ & 57.5 & $89 \%$ \\
Sample 5 & $6.5 \pm 0.4$ & $301.1 \pm 27.3$ & $<2$ & $25.9 \pm 1.1$ & 172.3 & $30 \%$ \\
Sample 6 & $3.5 \pm 0.8$ & $11.3 \pm 0.9$ & $<2$ & $14.8 \pm 0.9$ & 34.1 & $87 \%$ \\
Sample 7 & $3.5 \pm 0.3$ & $19.1 \pm 1.8$ & $<2$ & $23.5 \pm 1.9$ & 54.6 & $86 \%$ \\
\hline
\end{tabular}

\section{Conclusions}

We present a novel SFC-MS/MS method for the quantitation of vitamins D2, D3, and their main metabolites 25OHD3 and 25OHD2 in $1 \mathrm{~mL}$ of human milk. All analytes were separated on a Waters $\mathrm{CSH}^{\mathrm{TM}}$ Fluoro Phenyl column using a gradient of methanol-ammonium formate on carbon dioxide. Sample preparation ensured recovery of vitamin D metabolites and efficient removal of interfering compounds to achieve low detection limits. Quantitation limits were as low as $2 \mathrm{ng} / 100 \mathrm{~mL}$ of milk (corresponding to $50 \mathrm{pmol} / \mathrm{L}$ ), with method accuracy demonstrated by recovery from spike experiments well within acceptability limits $(100 \% \pm 15 \%)$ at two concentration levels and complemented with the analysis of a standard reference material. Within- and between-day variability (represented by standard deviation of repeatability and reproducibility) were below $15 \%$ and $20 \%$ respectively.

The method was successfully applied to human milk samples showing good potential for application to large clinical studies. As many as 50 samples can be analyzed on a single run, automation of sample preparation would increase throughput but the possibilities were not explored at this time. The newly developed method provides opportunities to determine nutritional status of mother-infant dyads from a non-invasive measure, or for interventional or observational studies building knowledge on the composition of human milk.

\section{Compliance with ethical standards}

Conflict of interest The authors declare that they have no conflict of interest.

Open Access This article is distributed under the terms of the Creative Commons Attribution 4.0 International License (http:// creativecommons.org/licenses/by/4.0/), which permits unrestricted use, distribution, and reproduction in any medium, provided you give appropriate credit to the original author(s) and the source, provide a link to the Creative Commons license, and indicate if changes were made.

\section{References}

1. Holick MF, Chen TC, Lu Z, Sauter E. Vitamin D and skin physiology: a D-lightful story. J Bone Miner Res: Journal of bone and mineral research. 2007;22(Suppl 2):V28-33.

2. Trang HM, Cole DE, Rubin LA, Pierratos A, Siu S, Vieth R. Evidence that vitamin D3 increases serum 25-hydroxyvitamin D more efficiently than does vitamin D2. Am J Clin Nutr. 1998;68(4):854-8.

3. Tripkovic L, Lambert H, Hart K, Smith CP, Bucca G, Penson S, et al. Comparison of vitamin D2 and vitamin D3 supplementation in raising serum 25-hydroxyvitamin D status: a systematic review and meta-analysis. Am J Clin Nutr. 2012;95(6):1357-64.

4. Holick MF, Biancuzzo RM, Chen TC, Klein EK, Young A, Bibuld $\mathrm{D}$, et al. Vitamin D2 is as effective as vitamin D3 in maintaining circulating concentrations of 25-hydroxyvitamin D. J Clin Endocrinol Metab. 2008;93(3):677-81.

5. Hollis BW, Roos BA, Draper HH, Lambert PW. Vitamin D and its metabolites in human and bovine milk. J Nutr. 1981;111(7):1240 8.

6. Reeve LE, Chesney RW, DeLuca HF. Vitamin D of human milk: identification of biologically active forms. Am J Clin Nutr. 1982;36(1):122-6.

7. Weisman Y, Bawnik JC, Eisenberg Z, Spirer Z. Vitamin D metabolites in human milk. J Pediatr. 1982;100(5):745-8.

8. Parviainen MT, Koskinen T, Ala-Houhala M, Visakorpi JK. A method for routine estimation of vitamin D activity in human and bovine milk. Acta Vitaminol Enzymol. 1984;6(3):211-9.

9. Takeuchi A, Okano T, Tsugawa N, Tasaka Y, Kobayashi T, Kodama $\mathrm{S}$, et al. Effects of ergocalciferol supplementation on the concentration of vitamin D and its metabolites in human milk. J Nutr. 1989;119(11):1639-46.

10. Volmer DA, Mendes LR, Stokes CS. Analysis of vitamin D metabolic markers by mass spectrometry: current techniques, limitations of the "gold standard" method, and anticipated future directions. Mass Spectrom Rev. 2015;34(1):2-23.

11. Wallace AM, Gibson S, de la Hunty A, Lamberg-Allardt C, Ashwell M. Measurement of 25-hydroxyvitamin D in the clinical laboratory: current procedures, performance characteristics and limitations. Steroids. 2010;75(7):477-88.

12. Higashi T, Shimada K, Toyo'oka T. Advances in determination of vitamin D related compounds in biological samples using liquid chromatography-mass spectrometry: a review. J. Chromatogr. B. 2010;878(20):1654-61

13. Kasalová E, Aufartová J, Krčmová LK, Solichová D, Solich P. Recent trends in the analysis of vitamin D and its metabolites in milk - a review. Food Chem. 2015;171:177-90.

14. Gomes FP, Shaw PN, Whitfield K, Koorts P, Hewavitharana AK. Recent trends in the determination of vitamin D. Bioanalysis. 2013;5(24):3063-78. 
15. Aronov PA, Hall LM, Dettmer K, Stephensen CB, Hammock BD. Metabolic profiling of major vitamin D metabolites using DielsAlder derivatization and ultra-performance liquid chromatography-tandem mass spectrometry. Anal Bioanal Chem. 2008;391(5):1917-30.

16. Kamao M, Tsugawa N, Suhara Y, Wada A, Mori T, Murata K, et al. Quantification of fat-soluble vitamins in human breast milk by liquid chromatography-tandem mass spectrometry. J Chromatogr B Anal Technol Biomed Life Sci. 2007;859(2):192-200.

17. Gomes FP, Shaw PN, Whitfield K, Hewavitharana AK. Simultaneous quantitative analysis of eight vitamin D analogues in milk using liquid chromatography-tandem mass spectrometry. Anal Chim Acta. 2015;891:211-20.

18. Stoutjesdijk E, Schaafsma A, Nhien NV, Khor GL, Kema IP, Hollis $\mathrm{BW}$, et al. Milk vitamin D in relation to the 'adequate intake' for 06-month-old infants: a study in lactating women with different cultural backgrounds, living at different latitudes. Br J Nutr. 2017;118(10):804-12 1-9.

19. Klesper E, Corwin AH, Turner DA. High pressure gas chromatography above critical temperatures. J Organomet Chem. 1962;27(2): $700-5$.

20. Grand-Guillaume Perrenoud A, Veuthey J-L, Guillarme D. Comparison of ultra-high performance supercritical fluid chromatography and ultra-high performance liquid chromatography for the analysis of pharmaceutical compounds. JChromatogr A. 2012;1266(Supplement C):158-67.

21. Fekete S, Veuthey J-L, Guillarme D. Comparison of the most recent chromatographic approaches applied for fast and high resolution separations: theory and practice. J Chromatogr A. 2015;1408(Supplement C):1-14.

22. Grand-Guillaume Perrenoud A, Hamman C, Goel M, Veuthey J-L, Guillarme D, Fekete S. Maximizing kinetic performance in supercritical fluid chromatography using state-of-the-art instruments. J Chromatogr A. 2013;1314(Supplement C):288-97.

23. Jenkinson C, Taylor A, Storbeck KH, Hewison M. Analysis of multiple vitamin D metabolites by ultra-performance supercritical fluid chromatography-tandem mass spectrometry (UPSFC-MS/ MS). J Chromatogr B Anal Technol Biomed Life Sci. 2018;10871088:43-8

24. Jumaah F, Larsson S, Essen S, Cunico LP, Holm C, Turner C, et al. A rapid method for the separation of vitamin $\mathrm{D}$ and its metabolites by ultra-high performance supercritical fluid chromatography-mass spectrometry. J Chromatogr A. 2016;1440:191-200.

25. Oberson J-M, Campos-Giménez E, Rivière J, Martin F. Application of supercritical fluid chromatography coupled to mass spectrometry to the determination of fat-soluble vitamins in selected food products. J. Chromatogr., B Analyt Technol. Biomed. Life Sci. 2018;1086:118-29.

26. Levêques A, Oberson JM, Tissot EA, Redeuil K, Thakkar SK, Campos-Giménez E. Quantification of vitamins A, E, K and carotenoids in sub-milliliter volumes of human milk. J AOAC Int. 2019;102(4):1059-68.

27. Trisconi MJ, Campos-Gimenez E, Jaudzems G, Dowell D. Determination of vitamin A in infant formula and adult nutritionals by UPLC-UV: First Action 2011.07. J. AOAC Int. 2012;95(2): $301-6$.

28. Traceability NIS. Standard Reference Material 1849a Infant/Adult Nutritional (https://www-s.nist.gov/srmors/certificates/1849a.pdf). https://www-s.nist.gov/srmors/certificates/1849a.pdf. Accessed Jan 2019.

29. van den Ouweland JMW, Beijers AM, van Daal H. Overestimation of 25-hydroxyvitamin D3 by increased ionisation efficiency of 3epi-25-hydroxyvitamin D3 in LC-MS/MS methods not separating both metabolites as determined by an LC-MS/MS method for separate quantification of 25-hydroxyvitamin D3, 3-epi-25hydroxyvitamin D3 and 25-hydroxyvitamin D2 in human serum. J. Chromatogr., B Analyt Technol. Biomed. Life Sci. 2014;967: 195-202.

30. Desfontaine V, Tarafder A, Hill J, Fairchild J, Grand-Guillaume Perrenoud A, Veuthey J-L, et al. A systematic investigation of sample diluents in modern supercritical fluid chromatography. J Chromatogr A. 2017;1511(Supplement C):122-31.

31. ISO 20636:2015 Infant formula and adult nutritionals Determination of vitamin D.

32. Hewavitharana AK. Matrix matching in liquid chromatographymass spectrometry with stable isotope labelled internal standards - Is it necessary? J Chromatogr A. 2011;1218(2):359-61.

33. Taylor SN, Wagner CL, Hollis BW. Vitamin D supplementation during lactation to support infant and mother. J Am Coll Nutr. 2008;27(6):690-701.

34. Hollis BW, Pittard WB, Reinhardt TA. Relationships among vitamin $\mathrm{d}, 25$-hydroxyvitamin $\mathrm{D}$, and vitamin D-binding protein concentrations in the plasma and milk of human subjects. J Clin Endocrinol Metab. 1986;62(1):41-4.

Publisher's note Springer Nature remains neutral with regard to jurisdictional claims in published maps and institutional affiliations. 